Article Type: Full Paper

\title{
Sprouted and freeze-dried wheat and oat seeds - phytochemical profile and in vitro biological activities
}

\author{
Naji Elhadi Aborus, ${ }^{a}$ Vesna Tumbas Šaponjac, ${ }^{* a}$ Jasna Čanadanović-Brunet, ${ }^{a}$ Gordana Ćetković, ${ }^{a}$ \\ Alyssa Hidalgo, ${ }^{a}$ Jelena Vulić, ${ }^{a}$ Vanja Šeregelj ${ }^{a}$ \\ a University of Novi Sad, Faculty of Technology, Bulevar cara Lazara 1, 21000 Novi Sad, Serbia, e-mail: \\ vesnat@uns.ac.rs \\ ${ }^{\mathrm{b}}$ Department of Food, Environmental and Nutritional Sciences (DeFENS), University of Milan, Via \\ Celoria 2, 20133 Milan, Italy
}

\begin{abstract}
This research was carried out to study phytochemical profile, in vitro antioxidant capacity, reducing power, anti-hyperglycemic, anti-inflammatory activities, and simulated gastrointestinal digestion of seven-day old cereal sprouts: spelt wheat 'Nirvana' (WSSpe), wheat 'Simonida' (WSSim), oat 'Golozrni' (OSG) and oat 'Jadar' (OSJ). OSG expressed significantly higher ( $P \leq 0.05)$ total phenols (TPC) and flavonoids content (TFC), antioxidant capacities (DPPH and ABTS assays) and reducing power $\left(\mathrm{EC}_{50}{ }^{\mathrm{DPPH}}=2.12 \mathrm{mg} / \mathrm{mL} ; \mathrm{EC}_{50}{ }^{\mathrm{ABTS}}=0.87 \mathrm{mg} / \mathrm{mL} ; \mathrm{EC}_{0.5}{ }^{\mathrm{RP}}=12.24 \mathrm{mg} / \mathrm{mL}\right.$ ) as well as antihyperglycemic activity $\left(\mathrm{EC}_{50}{ }^{\mathrm{AHgA}}=0.96 \mathrm{mg} / \mathrm{mL}\right)$. WSSpe had the highest content of chlorophyll $(131.23$ $\mathrm{mg} / 100 \mathrm{~g}$ ) and carotenoids $(22.84 \mathrm{mg} / 100 \mathrm{~g})$. WSSim possessed the most potent anti-inflammatory activity $(2.71 \mathrm{mg} / \mathrm{mL})$, though not significantly different from OSG $(2.77 \mathrm{mg} / \mathrm{mL})$. The in vitro simulation of gastro-intestinal digestion showed higher release of phenolic compounds in intestinal than in gastric fluid.
\end{abstract}

Keywords: anti-inflammatory activity $\bullet$ antioxidant capacity $\bullet$ pigments $\bullet$ freeze-drying $\bullet$ polyphenols

\section{Introduction}

In recent years, sprouts have received much attention as functional foods in many countries, especially in Europe, United States of America and Japan, because of their superior nutritious and health benefits compared to seeds. Numerous studies have shown that the nutritional and chemical profile is altered following germination of cereal grains [1, 2]. Besides nutrients (vitamins, minerals and amino acids) sprouts have relevant amounts of antioxidants (phenolics and flavonoids), contributing to preservation of human health [3].

Sprouting has been shown to increase the activity of hydrolytic enzymes which largely affects nutritional components in a beneficial way. For example, polysaccharides and protenis are broken This article has been accepted for publication and undergone full peer review but has not been through the copyediting, typesetting, pagination and proofreading process, which may lead to differences between this version and the Version of Record. Please cite this article as doi: 10.1002/cbdv.201800119

This article is protected by copyright. All rights reserved. 
down into building units producing reducing sugars, soluble dietary fibres, peptides and amino acids, and leading to detachment of polyphenols from cell walls [4, 5]. Additionally, the synthesis of tocopherols, niacin and riboflavin can occur during sprouting [6].

Oats have a reputation as a health-promoting food due to rich fiber fraction, but also fatty acids, sterols, proteins, tocols and phenolic compounds. However, only $25 \%$ of produced oats worldwide is used for food, while more than $50 \%$ is used as feed [7]. Wheat is the most common grown cereal crop, with more than $25 \%$ of world's cereal production. Wheat is mostly used for food, while only $15 \%$ is exploited in feed [8]. Due its composition wheat is suitable for preparing bread, a variety of bakery products and pasta, it makes wheat one of the most abundant food ingredients in our diet. Wheat grain contains proteins (10-18\%), starch (60-65\%), small amounts of lipids, dietary fibre, vitamins, tocols, carotenoids, minerals, iron and selenium [9].

Several studies have reported that fresh fruits and vegetables are good sources of nutrients, dietary fibre, minerals and phenolic compounds [10]. But they are usually seasonal and therefore out of season they are expensive, cultivated under artificial condition, prematurely harvested and exported to other parts of world. All these factors result in a decline of nutritional value of the crops. Thus, cereal sprouts, which can be consumed in fresh form at all times of the year, are inexpensive and have high nutritional values, may represent a good alternative.

Water, as the dominant component of foods, provides the critical environment for the ubiquitous biological, biochemical and biophysical processes that degrade foods and ultimately make them unfit for human consumption. Among many drying methods, freeze-drying is the most preferable process for manufacturing high-quality dehydrated products (e.g. vegetables, teas, aromatic herbs, coffee) since it preserves most of the initial raw material properties such taste, flavour, biological activity, etc. [11].

To the best of our knowledge, not many studies focused on the relationship between phytochemicals and their biological values of cereal sprouts, especially wheat and oats, are currently available. Additionally, freeze-dried wheat and oat sprouts in powdered form have not been yet considered as functional food ingredients. Therefore, aim of this study was to investigate powdered wheat and oat sprouts to determine if they possess effective physiologically bioactive compounds, i.e. phenolics, flavonoids, chlorophylls and carotenoids, able to express antioxidant capacity, antihyperglycemic and anti-inflammatory activities, as well as to study the behaviour of phenolic compounds during simulated digestion. These properties would enable the use of freeze-dried wheat and oat sprouts to reduce the risk of some diseases, in addition to their nutritional value, so that they may be used in food fortification to enhance nutritional and functional value.

This article is protected by copyright. All rights reserved. 


\section{Results and Discussion}

Pigments and colour measurements

The pigments content, i.e. total chlorophyll (TChl), chlorophyll a (Chl a), chlorophyll b (Chl b), and total carotenoids (TC), measured in freeze-dried sprout powders (FDSP) are shown in Table 1. FDSP of spelt wheat 'Nirvana' (WSSpe) had the highest ( $p \leq 0.05)$ value of TChl (131.23 mg/100 g), followed by FDSP of wheat 'Simonida' (WSSim), oat 'Jadar' (OSJ) and oat 'Golozrni' (OSG). Wheat sprouts (WS) were significantly higher ( $p \leq 0.05$ ) in TChl than oat sprouts (OS). Both WS showed much higher ( $p \leq 0.05$ ) According to the reports of De Nicola et al. [12] cereal sprouts have higher contents of chlorophylls than Brassica sprouts.

Chl $a$ and $\mathrm{Chl} b$ were also highest in WSSpe $(p \leq 0.05)$ than in other investigated sprouts, while the lowest were in OSG. It is worth mentioning that the $\mathrm{Chl}$ a in all investigated FDSP represented about 66 to $67 \%$ of TChl content, while Chl b was about 20 - $21 \%$ of TChl. According to the theory of optimal nitrogen partitioning within a leaf, the $\mathrm{Chl} \mathrm{a} / \mathrm{b}$ ratio is expected to increase when leaf $\mathrm{N}$ content decreases. In our study, $\mathrm{Chl}$ a/b was in the range 3.02 to 3.21 . Our results are in agreement with the reports of Busheva et al. [13] who found that 6-day old young wheat leaves had Chl a/b ratios between $2.7-3.1$, depending on the part of the leaf; young wheat leaves from their base to the tip exhibited a gradual increase in the $\mathrm{Chl}$ content per unit area and a decrease in the $\mathrm{Chl} \mathrm{a/b}$ ratio.

Carotenoids, including carotenes and xanthophylls, are antioxidant nutrients that act mainly as secondary antioxidants by quenching singlet oxygen. Both WS had higher TC values than OS ( $p \leq$ 0.05). No significant difference was observed between WSSpe and WSSim, as well as between OSJ and OSG. Mattioli et al. [14] reported carotenoid content in 3-day old flax sprouts (13.72 mg/100 g) similar to OS sprouts, while the content of carotenoids in 3-day old alfalfa sprouts (106.3 mg/100 g) was much higher than that of all FDSP tested in our study. In the study of Mattioli et al. [14] alfalfa and flax sprouts were used to supplement hen's diet, increasing the n-3 PUFA, vitamin, carotene, and phytoestrogen contents of eggs. It is interesting to note that the presence of various pigments such as chlorophylls and carotenoids in sprouts may greatly influence the colour of fortified products. Plaza et al. [15] have reported that sprouting caused a significant increase in vitamin A activity in soybean and in alfalfa. Vitamin $A$ was quantified by measuring $\beta$-carotene content and expressed as retinol equivalents ( $R E=\mu g \beta$-carotene/6). The greatest vitamin $A$ content was found in alfalfa sprouts (531.89 RE/100 $\mathrm{g} \mathrm{dm}$ ). It was calculated that, on a fresh weight basis, a $350 \mathrm{~g}$ serving of fresh alfalfa sprouts is enough to supply one third of the recommended dietary allowance for vitamin A for women (RE $700 \mu \mathrm{g}$ ). Still, total carotenoid contents for OS and WS in this study (15.27$22.84 \mathrm{mg} \beta$-carotene/100 $\mathrm{mg} \mathrm{dm}$ ) were 5-7 times higher than in alfalfa sprouts.

The mean values of the CIE colour coordinates obtained in FDSP are also shown in Table 1. Significant differences in colour characteristics were found among FDSP ( $p \leq 0.05)$. As presented, $b^{*}$ values were positive, while $a^{*}$ values were negative in all investigated sprouts. The highest and the lowest lightness $L^{*}$ values were observed in OSG and WSSim, respectively. Therefore, it could be concluded that the FDSP were bright ( $L^{*}: 27.01$ to 28.59) and showed a shade of green based on chlorophyll pigments. The greenness value $\left(a^{*}\right)$ was higher in both WS (-1.81 and -1.63), and lower in both OS (-1.62 and -1.62). The negative values of $a^{*}$ are related to chlorophyll pigments. Total

This article is protected by copyright. All rights reserved. 
chlorophyll values are in conformity with a* values, based on the Parsons' correlation coefficient ( $r=$ 0.76). Chroma ranged from 8.16 to 10.03 for all FDSP, with lower values in WS than in OS samples. Differently, the WS showed higher hue values.

Table 1. Spectrophotometrical analysis and CIE parameters of pigments (chlorophylls and total carotenoids) in freeze-dried sprout powders

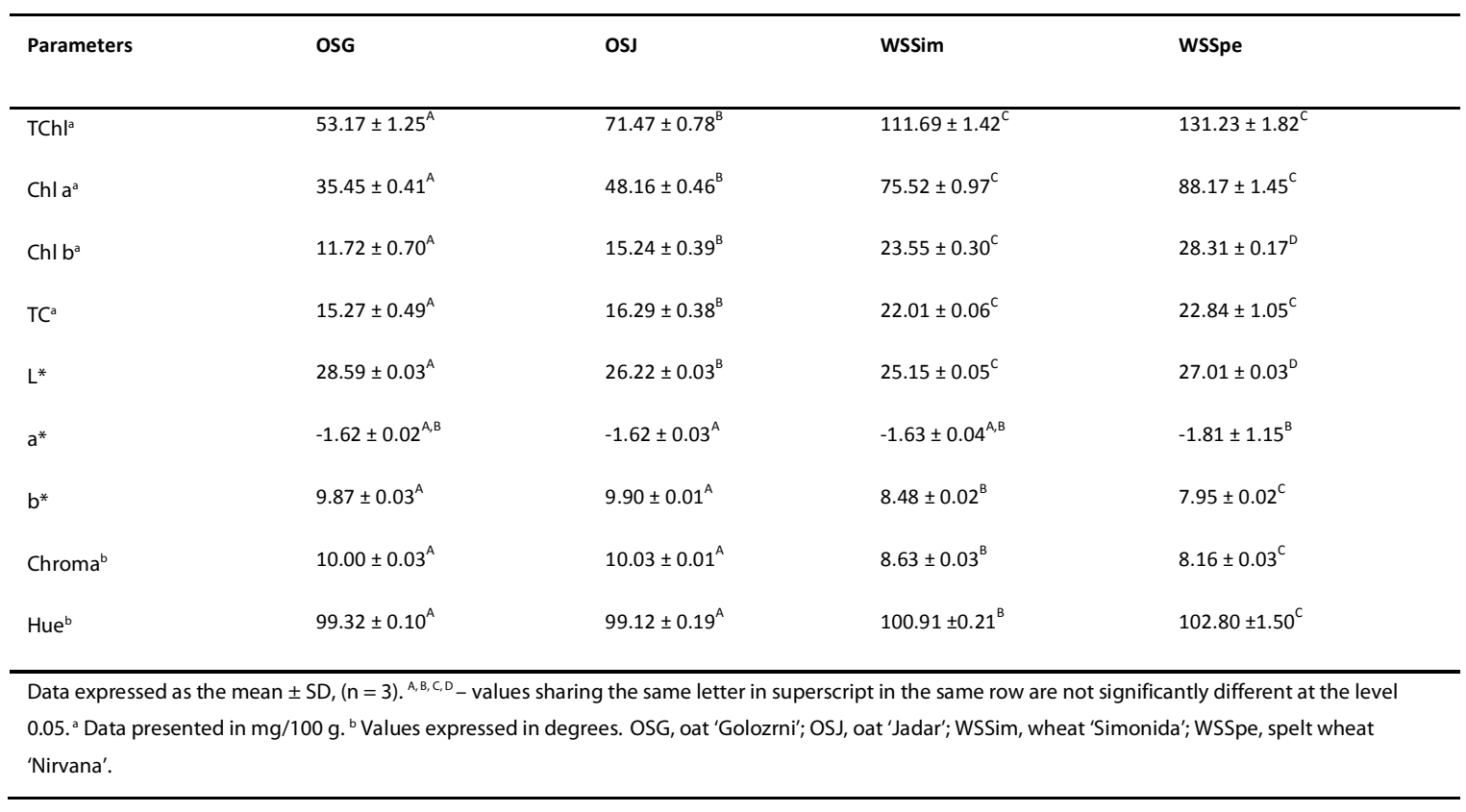

Content of total and individual phenolics in FDSP

Total polyphenol (TPC) and total flavonoid contents (TFC) in FDSP are summarized in Table 2. It can be seen that OSG and WSSim possessed higher TPC than WSSpe and OSJ ( $p \leq 0.05)$. The TPC of OSJ and WSSim was similar to the level reported by Alvarez-Jubete et al. [16] for buckwheat sprouts (670 $\mathrm{mg} \mathrm{GAE} / 100 \mathrm{~g}$ ) and higher than the level reported by the same authors for wheat sprouts (110 $\mathrm{mg}$ $\mathrm{GAE} / 100 \mathrm{~g}$ ). The range of TPC found in our samples was slightly lower than that reported by Aborus et al. [17] for two barley varieties (from 479 to $713 \mathrm{mg} / 100 \mathrm{~g}$ ).

Hung et al. [4] have followed the amount of free and bound phenolics in waxy wheat during 48 hours of germination. The content of free phenolics did not change significantly during the first $24 \mathrm{~h}$ of germination, but increased significantly after 36 and $48 \mathrm{~h}$. The increase in free phenolic content was due to the increase in syringic acid [4], as evident also from our results, which show substantial amounts of this phenolic acid in WSSim and WSSpe (Table 2). Žilić et al. [6] reported that total phenolic content in 5-day old sprouted wheat was $1957 \mathrm{mg} \mathrm{GAE} / \mathrm{kg}$, much lower than for WSSpe and WSSim in this study, probably due to shorter germination time.

Tian et al. [18] demonstrated the increase in TPC during germination of oat seeds from 0.20 (raw seeds) to $0.91 \mathrm{mg} \mathrm{GAE} / \mathrm{g}$ flour (after 6 days). This result is still much lower than the TPC values of 7day old OS presented in this study, probably because of different sample preparation, but also of the

This article is protected by copyright. All rights reserved. 
germination time. Our powdered sprout samples included the grains, shoots and roots, while in the study of Tian et al. [18] shoots and roots were removed before milling.

The OSG sample had the highest TFC ( $p \leq 0.05)$, followed by WSSpe, WSSim and OSJ. The statistical analysis showed highly significant difference between all investigated sprouts $(p \leq 0.05)$. TFC values ranged from 115.39-240.61 mg/100 g expressed as rutin equivalents, which is significantly lower than for Brassica oleracea L. sprouts ranging from 560 to $970 \mathrm{mg}$ catechin equivalents/100 g [12]. The increment or decrement in TFC as well as TPC may depend on genus, species, cultivar/genotype, harvesting time and germination conditions [19].

FDSP samples were subjected to HPLC analysis to determine the profile of the most abundant bioactive phenolic compounds (Table 2). Similar to TPC and TFC values, HPLC analysis confirmed that OSG contained significantly higher $(p \leq 0.05)$ total amount of phenolics $(476.74 \mathrm{mg} / 100 \mathrm{~g})$ than other sprouts (from 197.62 to $272.60 \mathrm{mg} / 100 \mathrm{~g}$ ), as a consequence of the higher flavonoids content. In both WS varieties, vanillic, protocatechuic, syringic, gallic and sinapic acids were the major phenolic compounds. Unlike WSSim, flavonoid myricetin was the dominant phenolic compound in WSSpe.

Table 2. Phenolic compounds in freeze-dried sprout powders

\begin{tabular}{|c|c|c|c|c|}
\hline Parameters & OSG & OSJ & WSSim & WSSpe \\
\hline TPC & $632.93 \pm 20.63^{A}$ & $367.24 \pm 2.57^{B}$ & $607.21 \pm 55.32^{A}$ & $373.31 \pm 19.56^{B}$ \\
\hline TFC & $240.61 \pm 3.50^{A}$ & $115.39 \pm 3.44^{B}$ & $195.46 \pm 5.21^{c}$ & $216.52 \pm 3.25^{c}$ \\
\hline \multicolumn{5}{|l|}{ Phenolic acids by HPLC } \\
\hline Gallic acid & $20.71 \pm 1.05^{\mathrm{A}}$ & $18.77 \pm 0.97^{A}$ & $25.91 \pm 0.68^{B}$ & $26.04 \pm 1.36^{B}$ \\
\hline Protocatechuic acid & $27.25 \pm 0.09^{A, B}$ & $24.06 \pm 0.13^{\mathrm{A}}$ & $29.29 \pm 2.01^{B}$ & $29.76 \pm 3.08^{B}$ \\
\hline Ferulic acid & $1.48 \pm 0.07^{\mathrm{A}}$ & $0.79 \pm 0.04^{B}$ & $2.49 \pm 0.07^{\mathrm{C}}$ & $2.20 \pm 0.16^{\mathrm{D}}$ \\
\hline Sinapic acid & $2.17 \pm 0.31^{\mathrm{A}}$ & $41.28 \pm 2.05^{B}$ & $20.02 \pm 1.67^{C}$ & $22.75 \pm 2.13^{C}$ \\
\hline Coumaric acid & $2.35 \pm 0.15^{\mathrm{A}}$ & nd & $6.48 \pm 0.99^{B}$ & $4.97 \pm 0.54^{B}$ \\
\hline$p$-Hydroxybenzoic acid & $44.37 \pm 2.06^{\mathrm{A}}$ & $20.90 \pm 0.98^{B}$ & $7.59 \pm 0.77^{c}$ & $8.04 \pm 0.83^{\mathrm{C}}$ \\
\hline Vanillic acid & nd & nd & $70.20 \pm 3.14^{\mathrm{A}}$ & $54.19 \pm 1.02^{\mathrm{B}}$ \\
\hline Caffeic acid & nd & nd & $2.07 \pm 0.33^{\mathrm{A}}$ & $2.34 \pm 0.55^{\mathrm{A}}$ \\
\hline Syringic acid & nd & nd & $26.49 \pm 1.04^{\mathrm{A}}$ & $44.50 \pm 1.09^{B}$ \\
\hline \multicolumn{5}{|l|}{ Flavonoids by HPLC } \\
\hline Myricetin & $146.62 \pm 2.99^{\mathrm{A}}$ & $97.11 \pm 1.06^{B}$ & $1.13 \pm 0.06^{C}$ & $67.81 \pm 1.85^{\mathrm{D}}$ \\
\hline Quercetin & $12.52 \pm 0.76^{A}$ & nd & $0.77 \pm 0.08^{B}$ & $2.95 \pm 0.68^{C}$ \\
\hline Kaempferol & $117.50 \pm 4.04^{A}$ & $9.17 \pm 1.22^{\mathrm{B}}$ & nd & nd \\
\hline Rutin & $37.23 \pm 0.87^{A}$ & $56.70 \pm 2.16^{\mathrm{B}}$ & $5.19 \pm 0.53^{C}$ & $7.05 \pm 0.44^{\mathrm{D}}$ \\
\hline Luteolin & $1.72 \pm 0.06$ & nd & nd & nd \\
\hline Apigenin & $33.79 \pm 1.62$ & nd & nd & nd \\
\hline Isorhamnetin & $29.01 \pm 0.95$ & nd & nd & nd \\
\hline Total phenolic acids HPLC & 38.34 & 105.79 & 190.54 & 194.80 \\
\hline Total flavonoids HPLC & 378.40 & 162.98 & 7.08 & 77.80 \\
\hline TPC HPLC & 476.74 & 268.77 & 197.62 & 272.60 \\
\hline
\end{tabular}

The oat sprouts investigated in this study had diverse phenolic profiles. Myricetin was found to be dominant in both OS, while kaempferol in OSG was about 13-fold higher than in OSJ. OSG also contained considerable amounts of $p$-hydroxybenzoic acid and rutin, while OSJ had 1.5-fold higher content of rutin and about 19-fold more sinapic acid compared to OSG. From the results of HPLC analysis it can also be concluded that OS contain significantly more flavonoids than phenolic acids ( $p$ $\leq 0.05)$, while WS showed the opposite trend.

These results are not consistent with the data reported by Hung et al. [20] where, after $80 \%$ aqueous ethanolic extraction of sprouted wheat flours, five phenolic compounds were found with a

This article is protected by copyright. All rights reserved. 
decreasing concentration order syringic $>$ sinapic $>$ ferulic $>$ coumaric $>$ caffeic acid. Besides the difference in sprouting time ( 2 days), the sample in their study included only sprouted seeds, while shoots and radicals were removed, unlike in our study. In our study four hydroxybenzoic acids (vanillic, syringic, protocatechuic and gallic acid) were found to be dominant phenolic acids in WS. This is in agreement with the reports of Hung et al. [20] stating that hydroxybenzoic acid derivatives can be easily extracted using alcohol. On the other hand, hydroxycinnamic acid derivatives can be released from the bound form by alkaline hydrolysis. Also, the phenolic acid profile and the concentration of individual phenolic acids are dependent on wheat varieties and growing location.

Aborus et al. [17] studied the sprouts obtained from two varieties of barley and demonstrated that the vanillic, catechin, epicatechin and gallic acid were the most abundant phenolic acids. Generally, cereals have only small quantities of flavonoids, except barley seeds and sprouts that contain measurable amounts of flavonoids such as catechin, epicatechin [21]. Pajak et al. [2] reported that the free phenolic acids and flavonoids in seven-day old mung bean, radish, broccoli and sunflower sprouts were gallic, protocatechuic, caffeic, $p$-coumaric, ferulic, chlorogenic and sinapic acids, whereas the flavonoids were quercetin, kaempferol, luteolin and apigenin. The differences between phenolic contents reported in various studies could result from multiple factors, such as methodology (extraction procedure, different susceptibilities to degradation, type of chromatography and quantification), plant species, growth and storage environments etc. [22].

\section{In vitro gastrointestinal digestion of FDSP}

Gastrointestinal FDSP digestion was determined in vitro by exposing the powders to artificial gastric and intestinal fluids, separately, simulating in vivo conditions $(\mathrm{pH}$, temperature and shaking). Lower contents of polyphenols for all FDSP in gastric fluid indicates good stability during gastric digestion conditions caused, while higher release of polyphenols occurs in intestine (Figure 1). When the OSG was subjected to digestion, about $95 \%$ of TPC were found in simulated intestinal fluid (SIF), while 91\% were in simulated gastric fluid (SGF). OSJ released about 92\% of TPC in SIF and $44 \%$ in SGF; WSSpe and WSSim released about 56\% and $94 \%$ in SIF and $39 \%$ and $72 \%$ in SGF, respectively. The highest release of polyphenols in gastric and intestinal digestion conditions occurres with OSG suggesting highest digestibility of this oat variety. The lowest digestibility of polyphenols was found for WSSpe sample.

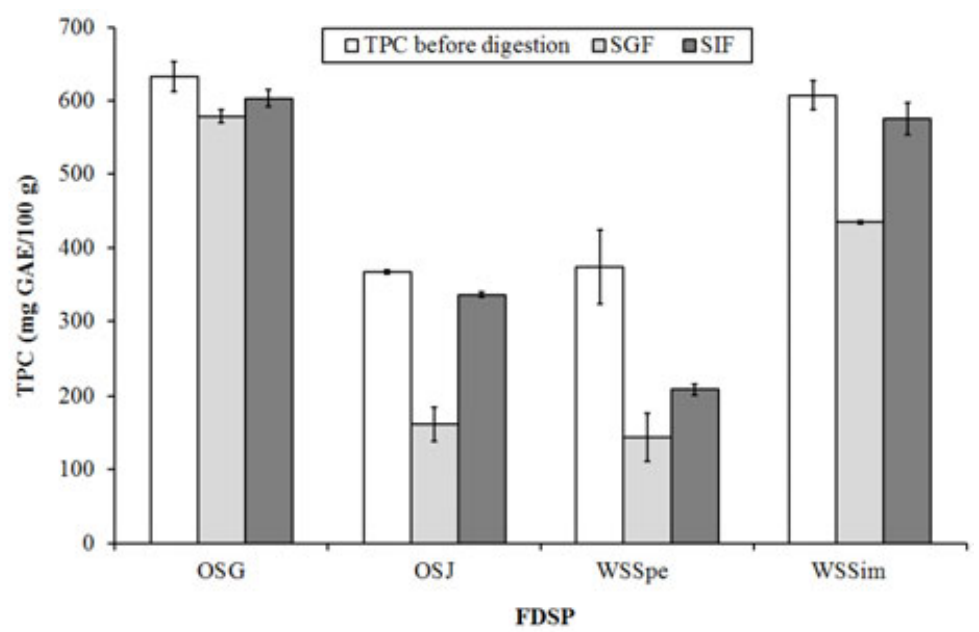

This article is protected by copyright. All rights reserved. 
Figure 1. In vitro gastrointestinal release of total polyphenols (TPC) from freeze-dried sprout powders (OSG, oat 'Golozrni'; OSJ, oat 'Jadar'; WSSim, wheat 'Simonida'; WSSpe, spelt wheat 'Nirvana') in simulated gastric (SGF) and intestinal fluids (SIF)

Aborus et al. [17] observed that intestinal digestion caused higher release of polyphenols (recovery from $72.73 \%$ to $94.97 \%$ ) than gastric digestion (recovery from $60.92 \%$ to $87.59 \%$ ) in two varieties of barley sprouts.

Simulated digestion studies are important for determining the release of food components during digestion which enables the biological properties of foods due to the interactions of compounds released into digestion fluids and with the intestinal epithelium. The digestion process depends on the sensitivity to digestive enzymes (pepsin and pancreatin), $\mathrm{pH}$, and chemical structure of targeted compounds [17]. On the other hand, Green et al. [23] demonstrated that $\mathrm{pH}$ conditions rather than digestive enzymes were responsible for sensitivity and release of phenols such as catechins, epigallocatechin and epigallocatechin-gallate.
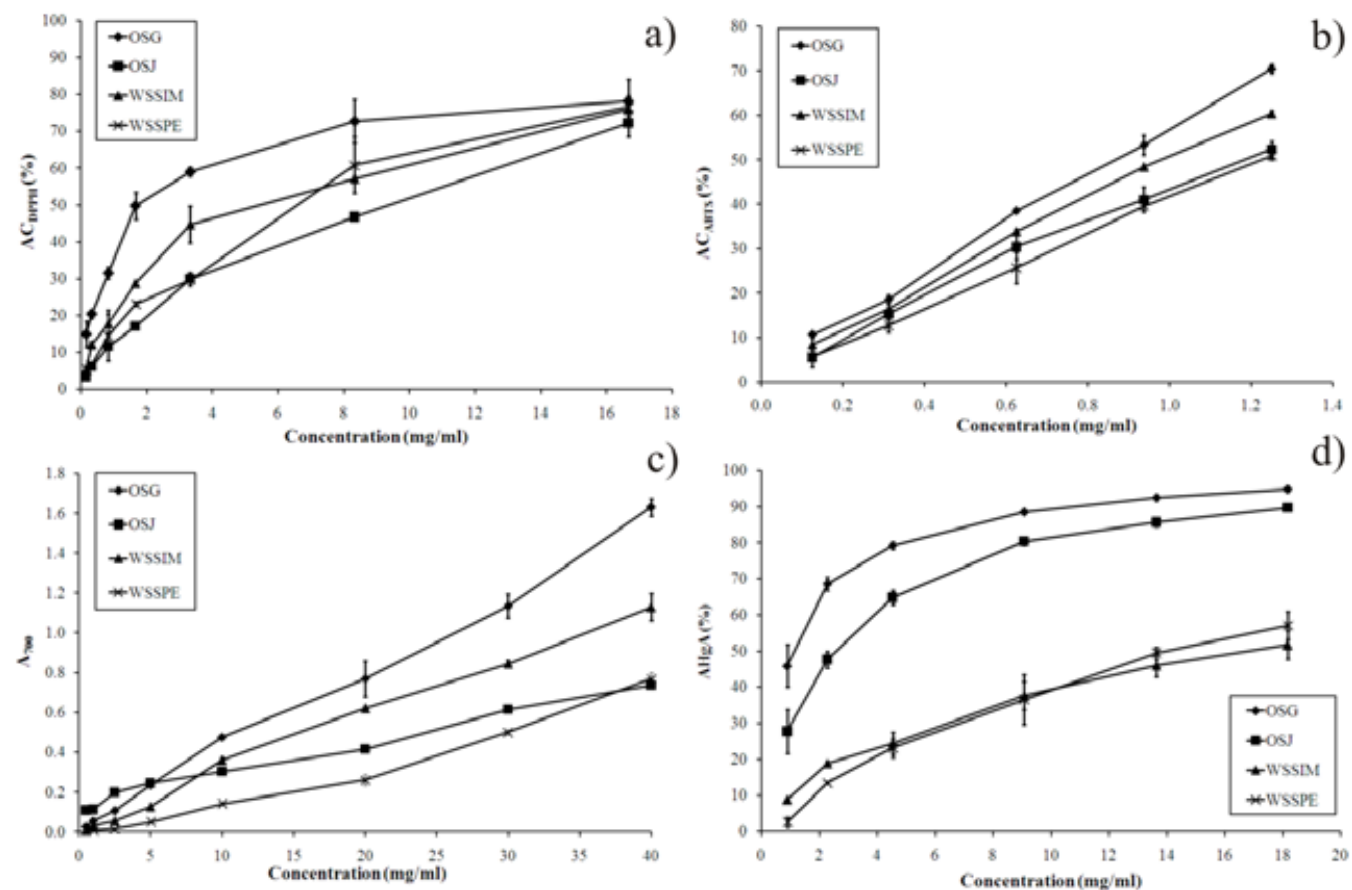

c)

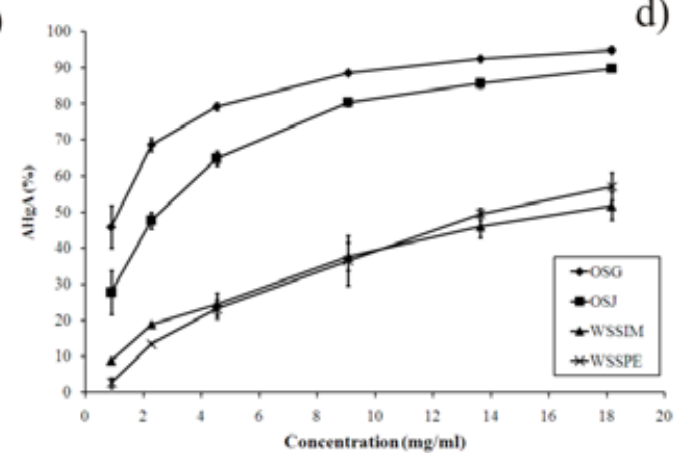

Figure 2. Antioxidant capacity in DPPH (a) and ABTS (b) assays, reducing power (c) and anti-hyperglycemic activity (d) of freeze-dried sprout powders

Antioxidant capacity (AC)

In order to test the antioxidant capacity potential of FDSP, the in vitro DPPH (2,2-diphenyl-1picrylhydrazyl) assay was employed (Figure 1a). The $\mathrm{EC}_{50}{ }^{\mathrm{DPPH}}$ of FDSP are listed in Table 3. The $\mathrm{EC}_{50}{ }^{\mathrm{DPPH}}$ values ranged from 2.12 to $8.86 \mathrm{mg} / \mathrm{ml}$. The lowest $\mathrm{EC}_{50}{ }^{\mathrm{DPPH}}$ was observed in OSG while the highest was in OSJ $(p \leq 0.05)$. Scavenging effect on the DPPH radical decreased in the following order: OSG > WSSim > WSSpe > OSJ.

This article is protected by copyright. All rights reserved. 
Table 3. $\mathrm{EC}_{50}$ and $\mathrm{EC}_{0.5}$ values for freeze-dried sprout powders in bioactivity assays (DPPH and ABTS antioxidant capacity; reducing power, RP; antihyperglycemic activity, AHgA; anti-inflammatory activity, AIA)

\begin{tabular}{|c|c|c|c|c|c|}
\hline $\mathrm{EC}_{50}$ & Units & OSG & OSJ & WSSim & WSSpe \\
\hline \multirow[t]{3}{*}{$\mathrm{EC}_{50}{ }^{\mathrm{DPPH}}$} & $(\mathrm{mg} / \mathrm{ml})$ & $2.12 \pm 0.24^{A}$ & $8.86 \pm 0.07^{B}$ & $4.69 \pm 0.53^{C}$ & $5.67 \pm 0.75^{c}$ \\
\hline & $(\mathrm{mmol} T E / 100 \mathrm{~g})$ & $0.57 \pm 0.06^{A}$ & $0.13 \pm 0.00^{B}$ & $0.27 \pm 0.03^{C}$ & $0.24 \pm 0.03^{C}$ \\
\hline & (mg TE/100 g) & $141.49 \pm 15.41^{\mathrm{A}}$ & $33.58 \pm 0.27^{B}$ & $66.62 \pm 7.86^{c}$ & $59.67 \pm 8.16^{c}$ \\
\hline $1 / \mathrm{EC}_{50}{ }^{\mathrm{DPPH}}$ & (ml/mg) & $0.48 \pm 0.05^{A}$ & $0.11 \pm 0.00^{B}$ & $0.22 \pm 0.03^{c}$ & $0.18 \pm 0.02^{C}$ \\
\hline \multirow[t]{3}{*}{$\mathrm{EC}_{50}{ }^{\mathrm{ABTS}}$} & $(\mathrm{mg} / \mathrm{ml})$ & $0.87 \pm 0.01^{A}$ & $1.16 \pm 0.06^{B}$ & $1.00 \pm 0.01^{c}$ & $1.22 \pm 0.03^{B}$ \\
\hline & $(\mathrm{mmol} \mathrm{TE} / 100 \mathrm{~g})$ & $0.93 \pm 0.01^{A}$ & $0.69 \pm 0.03^{B}$ & $0.84 \pm 0.07^{c}$ & $0.75 \pm 0.02^{B}$ \\
\hline & (mg TE/100 g) & $232.24 \pm 3.12^{\mathrm{A}}$ & $173.80 \pm 8.73^{B}$ & $209.92 \pm 1.47^{c}$ & $186.90 \pm 3.93^{\mathrm{B}}$ \\
\hline $1 / \mathrm{EC}_{50}{ }^{\mathrm{ABTS}}$ & $(\mathrm{ml} / \mathrm{mg})$ & $1.15 \pm 0.02^{A}$ & $0.86 \pm 0.04^{B}$ & $1.00 \pm 0.00^{C}$ & $0.82 \pm 0.02^{B}$ \\
\hline \multirow[t]{3}{*}{$E C_{0.5}{ }^{R P}$} & $(\mathrm{mg} / \mathrm{ml})$ & $12.24 \pm 0.48^{A}$ & $24.58 \pm 0.04^{B}$ & $17.58 \pm 0.49^{C}$ & $25.83 \pm 0.17^{D}$ \\
\hline & (mmol TE/100 g) & $2.48 \pm 0.10^{A}$ & $1.23 \pm 0.00^{\mathrm{B}}$ & $1.80 \pm 0.05^{c}$ & $1.32 \pm 0.01^{D}$ \\
\hline & (mg TE/100 g) & $668.80 \pm 26.08^{A}$ & $323.85 \pm 0.52^{B}$ & $465.53 \pm 12.87^{C}$ & $316.68 \pm 2.04^{D}$ \\
\hline $1 / \mathrm{EC}_{0.5}{ }^{\mathrm{RP}}$ & (ml/mg) & $0.08 \pm 0.00^{A}$ & $0.04 \pm 0.00^{B}$ & $0.06 \pm 0.00^{c}$ & $0.04 \pm 0.00^{D}$ \\
\hline $\mathrm{EC}_{50}{ }^{\mathrm{AHgA}}$ & $(\mathrm{mg} / \mathrm{ml})$ & $0.96 \pm 0.24^{A}$ & $2.47 \pm 0.39^{B}$ & $17.28 \pm 0.82^{C}$ & $14.61 \pm 1.35^{D}$ \\
\hline $1 / \mathrm{EC}_{50}{ }^{\mathrm{AHgA}}$ & (ml/mg) & $1.11 \pm 0.02^{A}$ & $0.40 \pm 0.00^{B}$ & $0.06 \pm 0.00^{C}$ & $0.07 \pm 0.00^{\mathrm{D}}$ \\
\hline $\mathrm{EC}_{50}^{\mathrm{AlA}}$ & $(\mathrm{mg} / \mathrm{ml})$ & $2.77 \pm 0.05^{\mathrm{A}}$ & $4.77 \pm 0.56^{B}$ & $2.71 \pm 0.03^{A}$ & $3.70 \pm 0.38^{c}$ \\
\hline $1 / \mathrm{EC}_{50}{ }^{\mathrm{AIA}}$ & (ml/mg) & $0.36 \pm 0.01^{A}$ & $0.21 \pm 0.00^{B}$ & $0.37 \pm 0.07^{A}$ & $0.27 \pm 0.02^{C}$ \\
\hline
\end{tabular}

Data expressed as the mean $\pm S D,(n=3) .{ }^{A, B}, C, D$ - values sharing the same letter in superscript in the same row are not significantly different at the level 0.05 .

Alvarez-Jubete et al. [16], investigating the antioxidant capacity of buckwheat and wheat sprouts, reported that buckwheat and wheat sprouts possessed 666 and $73.7 \mathrm{mg}$ TE/100 g, respectively. Our results indicated that for all FDSP EC ${ }_{50}{ }^{\text {DPPH }}$ values were lower than buckwheat sprouts, only OSG expressed higher $\mathrm{AC}_{\mathrm{DPPH}}$ than wheat sprouts.

The antioxidant capacity of FDSP was further monitored by the $\mathrm{ABTS}^{+\bullet}\left(2,2^{\prime}\right.$-azino-bis(3ethylbenzothiazoline-6-sulphonic acid radcal cation) method, based upon the capacity of antioxidant compounds to scavenge radicals in $\mathrm{ABTS}^{+\bullet}$ solution in a hydrophilic medium. From the results presented in Table 3. and Figure $2 \mathrm{~b}$, it could be noticed that the highest $A_{C_{A B T S}}$ values were exhibited by OSG followed by WSSim, OSJ and WSSpe. The $\mathrm{EC}_{50}{ }^{\mathrm{ABTS}}$ ranged from $0.87 \mathrm{mg} / \mathrm{ml}$ in OSG to 1.22 $\mathrm{mg} / \mathrm{ml}$ in WSSpe. Pajak et al. [2] reported that the $A C_{A B T S}$ of mung bean, radish, broccoli, and sunflower sprouts ranged from 1133 to $2467 \mathrm{mg} \mathrm{TE} / 100 \mathrm{~g}$. According to those results, all FDSP in the current study showed lower $\mathrm{AC}_{\mathrm{ABTS}}$ than the data mentioned above.

This article is protected by copyright. All rights reserved. 
Reducing power (RP)

The reducing capacity of FDSP was introduced as another method for exploring antioxidant properties. The results of RP, presented in Table 3 and Figure 2c, showed that OSG exhibited the greatest reducing power, followed by WSSim, OSJ, and WSSpe.

Alvarez-Jubete et al. [16] investigated the antioxidant capacity of amaranth, quinoa, buckwheat and wheat sprouts. They reported that buckwheat and wheat sprouts possessed 739 and $210 \mathrm{mg}$ Trolox equivalents (TE)/100 g when the reducing power assay was used. Our results indicated that the RP values for FDSP were lower than for buckwheat, but higher than for wheat sprouts. Based on the results of $A C$ and $R P$, it could be concluded that these effects increase with increasing the concentration of polyphenols in the sprout sample. This hypothesis is demonstrated by several researchers such as Abdille et al. [24], Hodzic et al. [25], and Jayaprakasha and Patil [26].

Anti-hyperglycemic activity (AHgA)

Studies have shown that polyphenols from plants can cause insulin-like effects in glucose utilization, being effective inhibitors of intestinal $\alpha$-glucosidase activity [27]. The beneficial effects may lead to the applications of polyphenolic compounds as non-toxic alternatives to pharmaceutical treatments whereas polyphenolic-rich products may provide nutraceutical treatments for non-insulin dependent or type II diabetes and obesity [28].

The potential of FDSP tested for $\alpha$-glucosidase inhibition is presented in Figure $2 \mathrm{~d}$. A general trend showed that the inhibition of $\alpha$-glucosidase increased when the concentration of FDSP increased. OSG expressed significantly higher AHgA than other FDSP ( $p \leq 0.05)$, followed by OSJ. On the other hand, both WS showed low inhibitory effects. Donkor et al. [1] reported that higher inhibitory $\alpha$ glucosidase activity was observed in germinated sorghum (20\% AHgA), and germinated rye (12\% AHgA). Germinated barley showed higher inhibitory $\alpha$-glucosidase activity, compared to oat and brown rice, while it was similar to wheat and buckwheat.

Aborus et al. [17] reported that barley sprouts had $\mathrm{EC}_{50}{ }^{\mathrm{AHgA}}$ in the range $1.97-4.40 \mathrm{mg} / \mathrm{ml}$, which is comparable to the values obtained for OS in this study. Tumbas Šaponjac et al. [29] studied the influence of phytochemical compounds on $\alpha$-glucosidase activity from two strawberry varieties ('Clery' and 'Marmolada') and found that $\mathrm{EC}_{50}{ }^{\mathrm{AHgA}}$ values were in the range $0.60-1.90 \mathrm{mg} / \mathrm{ml}$, comparable to the activities obtained for OS in this study. The extent of $\alpha$-glucosidase inhibition was related to their phytochemical content. It can be proposed that different polyphenolic components of FDSP may influence different steps in starch digestion in a synergistic manner. The effectiveness of inhibition by different individual phenolic components depends on their site of action, their mechanism and their binding affinities, which could be modulated by synergistic or antagonistic actions [30]. This is also supported by the reports of Giampieri et al. [31] and McDougall et al. [32].

Anti-inflammatory activity (AIA)

The present findings exhibited a concentration-dependent inhibition of protein (albumin) denaturation by FDSP throughout the range 2.5 to $20 \mathrm{mg} / \mathrm{ml}$. Diclofenac sodium as the reference drug had a positive effect against protein denaturation even at lower concentrations ( 0.25 and 1.25 $\mathrm{mg} / \mathrm{ml}$, data not shown). The effect of Diclofenac sodium was higher $\left(\mathrm{EC}_{50}{ }^{\mathrm{AlA}}=0.79 \mathrm{mg} / \mathrm{ml}\right)$ than FDSP

This article is protected by copyright. All rights reserved. 
(Table 3). WSSim and OSG showed similar behaviour, while WSSpe and OSJ showed lower inhibition potentials.

The AIA of FDSP is reported in Table 3. The $\mathrm{EC}_{50}{ }^{\text {AlA }}$ values ranged from $2.77 \mathrm{mg} / \mathrm{ml}$ for OSG to 4.77 $\mathrm{mg} / \mathrm{ml}$ for OSJ. However, all FDSP showed lower AIA than Diclofenac sodium $\left(E C_{50}{ }^{\mathrm{AlA}}=0.79 \mathrm{mg} / \mathrm{ml}\right)$. Statistical analysis showed no significant difference $(p \leq 0.05)$ among WSSpe and OSJ $\mathrm{EC}_{50}{ }^{\mathrm{AIA}}$ values. Chandra et al. [33] reported that dried ripe seeds of Coffea arabica $\mathrm{L}$. possessed an $\mathrm{EC}_{50}{ }^{\mathrm{AlA}}$ value $0.004 \mathrm{mg} / \mathrm{ml}$. FDSP showed lower AIA than seeds of Coffea arabica L., used for medicinal purposes in the Indian subcontinent.

Avenanthramides are a group of phenolic compounds which exist exclusively in oat seeds and that have high anti-inflammatory, antiatherogenic and antioxidant bioactivities [34]. The process of steeping and germination results in increased levels of avenanthramides [35].

Correlation and PCA among phytochemical compounds and biological activities of FDSP For correlation analysis, $\mathrm{EC}_{50}{ }^{\mathrm{DPHH}}, \mathrm{EC}_{50}{ }^{\mathrm{ABTS}}, \mathrm{EC}_{0.5}{ }^{\mathrm{RP}}, \mathrm{EC}_{50}{ }^{\mathrm{AHgA}}$ and $\mathrm{EC}_{50}{ }^{\mathrm{AlA}}$ values were transformed into their reciprocal values $1 / \mathrm{EC}_{50}$ and $1 / \mathrm{EC}_{0.5}$, more representative because they follow the increasing trend of the sample efficiencies in the tested assays. These values were correlated with the amount of TPC, TFC, TChl, and TC quantified in FDSP. In order to evaluate the relationship between those phytochemicals and antioxidant capacities, reducing power, anti-hyperglycemic and antiinflammatory activities, Pearson's linear correlation coefficients $(r)$ were computed, and some strong significant correlations were observed $(0.8 \leq r \leq 1)$. The results of correlation analysis are presented in Table 4.

Table 4. Correlation coefficients ( $r$ ) between TPC, TFC, TChl, TC and the inverse of EC 50 values for DPPH, ABTS, RP, AIA, and AHgA for freeze-dried sprout powders $(n=4)$.

\begin{tabular}{lllll}
\hline Compounds vs. 1/EC & TFC & TPC & TChl & -0.45 \\
\hline $1 / \mathrm{EC}_{50}{ }^{\mathrm{DPPH}}$ & 0.78 & 0.76 & -0.54 & -0.49 \\
$1 / \mathrm{EC}_{50}{ }^{\mathrm{ABTS}}$ & 0.93 & 0.56 & -0.62 & -0.57 \\
$1 / \mathrm{EC}_{0.5}{ }^{\mathrm{RP}}$ & 0.93 & 0.65 & -0.56 & -0.86 \\
$1 / \mathrm{EC}_{50}{ }^{\text {AhgA }}$ & 0.47 & 0.31 & -0.89 & 0.13 \\
$1 / \mathrm{EC}_{50}{ }^{\mathrm{AlA}}$ & 0.94 & 0.75 & -0.03 & \\
\hline
\end{tabular}

TPC had strong correlation with antioxidant capacity measured by ABTS assay $(r=0.93)$. Also, strong correlation can be seen between TPC and reducing power $(r=0.93)$, whereas DPPH assay showed moderate positive correlation with TPC $(r=0.78)$ and with TFC $(r=0.76)$. Moderate positive correlation was also found between ABTS, RP and TFC. Vale et al. [36] reported that penca cabbage and red cabbage sprouts showed a maximum DPPH scavenging activity after 7 days of germination. These authors observed that DPPH scavenging activity was strongly related to the TPC in penca cabbage sprouts $(r=0.99)$, and with TFC $(r=0.89)$. It should be noted that our results are in accordance with those reported by Aires et al. [37], showing moderate positive correlation between TPC and DPPH ( $r=0.64)$ in Brassica vegetables (Brassica oleracea L. and Brassica rapa L.). Negative

This article is protected by copyright. All rights reserved. 
correlations were observed between TChl, TC and all biological activities of FDSP, except antiinflammatory activity.

The highest correlation coefficient $(r=0.94)$ was between TPC and AIA. The TFC was moderately correlated $(r=0.75)$ with AIA, while TPC $(r=0.47)$ and TFC $(r=0.31)$ showed moderate and weak correlations with $\mathrm{AHgA}$, respectively. It can be concluded that the antioxidant capacity, reducing power, anti-hyperglycemic and anti-inflammatory activities of extracts may differ depending on the quality of polyphenols (number and position of the hydroxyl groups) governing the mechanism of the reaction. This hypothesis is supported by Kouri et al. [38] and Wang and Mazza [39], because the mechanism of the reaction between the antioxidant and $\mathrm{ABTS}^{+\bullet}, \mathrm{DPPH}^{\bullet}$ as well as reducing power depends on the structural conformation of the antioxidant [38].

Plaza et al. [15] demonstrated that some compounds react rapidly with the ABTS ${ }^{+}$and DPPH radicals reducing their number. This decrease is equal to that of the hydroxyl groups of the antioxidant. Besides that, the effect of other natural antioxidants such as vitamin $C$ and vitamin $E$, which could be present in cereals sprouts, may express synergistic effects with polyphenols [40].

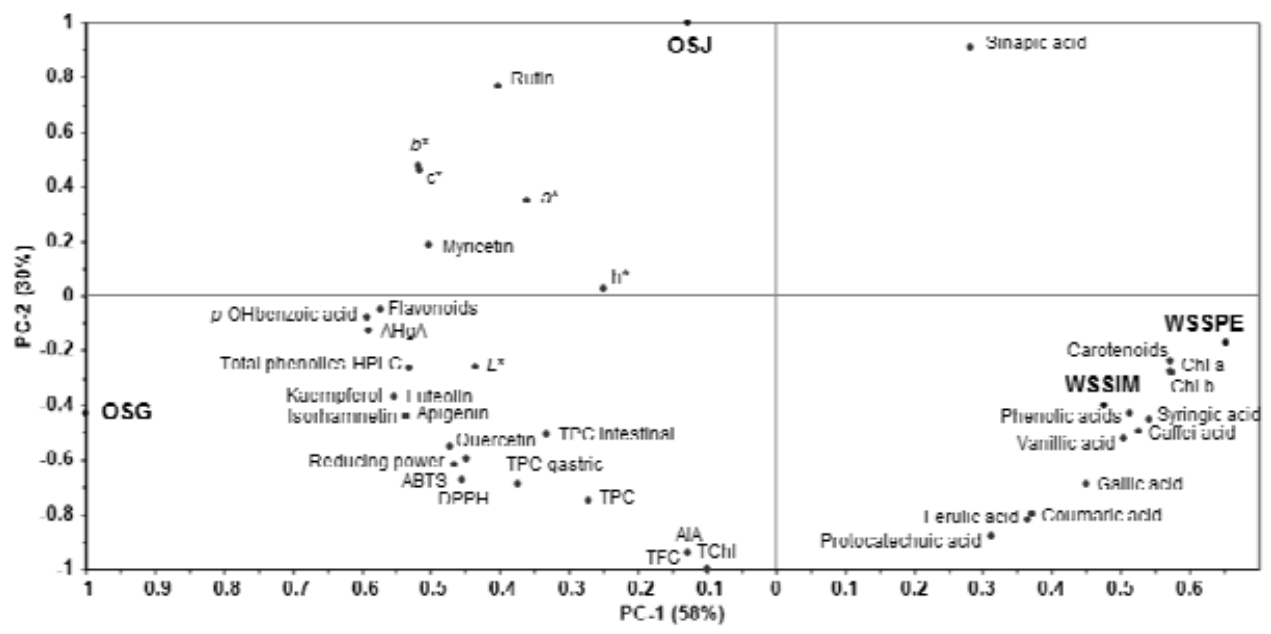

Figure 3. PCA of phytochemicals and bioactivities of freeze-dried sprout powders

Figure 3 depicts the bi-plot of sample scores and variable loadings (41 variables) in the PCA space of the first two components, which explain $88 \%$ of the total variance. Along PC1 (58\% of total variation) the samples were mainly separated according to the different phenolic profile. The two wheat sprout samples were placed on the right side because of their high phenolic acids and low flavonoids contents, as well as for their high total carotenoid and chlorophyll a and b levels. On the contrary OSG, particularly rich in flavonoids (the most abundant phenolic compounds) and with high antihyperglycemic and antioxidant activity, was placed on the left side. The other oat sprout, OSJ, was isolated along PC2 (30\% of total variation) because of its high rutin and sinapic acid content, as well as its low anti-inflammatory activity, total TFC and TChl. 


\section{Conclusions}

Our findings clearly demonstrate that 'Golozrni' oat sprouts showed higher antioxidant capacities, reducing power, and anti-hyperglycemic activities than sprouts from both wheat varieties as well as 'Jadar' oat sprouts. The correlation coefficient indicated strong and moderate positive correlations between TPC, TFC and DPPH, ATBS, and reducing power, while negative correlation was observed between pigments and all biological assays. According to the results obtained from FDSP anti-inflammatory activity, OSG and WSSim were found to be significantly more efficient against protein denaturation than other FDSP varieties. However, all FDSP showed lower AIA than Diclofenac sodium. This range of health benefits is probably due to the wide range of secondary metabolites contained within cereal sprouts. It can be proposed that the in vitro bioactivities of FDSP presented in our study can be attributed to the presence of the bioactive compounds TFC, TPC rather than to pigments. In vitro intestinal digestion caused higher release of polyphenols than in vitro gastric digestion in all FDSP, indicating a good stability in intestinal fluid.

The results of this study have shown that cereal sprouts can provide a high content of phytochemicals and considerable bioactivities. Moreover, data related to these cereal sprouts, here reported for the first time, show that they contain a unique pattern of bioactive molecules, which make these cereal sprouts attractive functional foods for a health-promoting diet. To sum up, the potential beneficial effects of the consumption of cereal sprouts, especially OSG, may be particularly expressed by using these sprouts for reducing the risk of some diseases; additionally, their nutritional value may be used in food development.

\section{Experimental Section}

Chemicals and instruments

All standards, enzymes and reagents used in this study were purchased from Sigma - Aldrich Co. (St. Louis, USA). Other chemicals and solvents of the highest commercial grade were purchased from Lach-Ner (Brno, Czech Republic). UV-1800 spectrophotometer (Shimadzu, Kyoto, Japan) was used for all spectrophotometrical measurements, except the $\alpha$-glucosidase assay for a Multiskan GO microplate reader (Thermo Fisher Scientific Inc., Waltham, MA, USA) was used. Chromatographic analyses were executed using Shimadzu Prominence HPLC, connected to a SPD-20AV UV/Vis detector (Shimadzu, Kyoto, Japan). CIE-LAB colour measurements were carried out with a portable Minolta Chroma Meter CR-300 (Minolta, Osaka, Japan).

Plant material and germination conditions

The four varieties of the cereals investigated in this study were: spelt wheat cv. 'Nirvana' (Triticum aestivum ssp. spelta L.), winter wheat cv. 'Simonida' (Triticum aestivum L. ssp. vulgare), spring oat cv. 'Golozrni' (Avena sativa L. var. nuda), and winter oat cv. 'NS Jadar' (Avena sativa L.). Cereal seeds were from the Institute of Field and Vegetable Crops (NS seme), Novi Sad, Serbia. Germination was carried out for 7 days, according to Aborus et al. [17]. After germination sprouts were freeze-dried (Alpha 2-4 LSC Martin Christ, Osterode, Germany), ground and passed through a $0.5 \mathrm{~mm}$ sieve. The freeze-dried sprouts powders, FDSP, (spelt wheat cv. 'Nirvana' (WSSpe), winter wheat cv. 'Simonida' (WSSim), spring oat cv. 'Golozrni' (OSG), and winter oat cv. 'NS Jadar' (OSJ)) were packed in vacuumed plastic bags and stored at $-20^{\circ} \mathrm{C}$.

This article is protected by copyright. All rights reserved. 
Preparation of FDSP extracts

For analysis of chlorophylls and carotenoids content, $25 \mathrm{mg}$ of FDSP was extracted with $5 \mathrm{ml}$ of acetone (99.5\%) in an ultrasonic bath for $20 \mathrm{~min}$, and then on a laboratory shaker at $200 \mathrm{rpm}$ (Unimax 1010, Heidolph Instruments $\mathrm{GmbH}$, Kelheim, Germany) for $2 \mathrm{~h}$. For total phenolic, total flavonoid, antioxidant capacity and reducing power assays, the same procedure was used but with $10 \mathrm{~g}$ of FDSP and $100 \mathrm{ml}$ of methanol $(70 \%, \mathrm{v} / \mathrm{v})$. All extractions were carried out under light protection and on room temperature. Extracts were filtered through Whatman paper No. 1.

For HPLC analysis, $100 \mathrm{mg}$ of FDSP was extracted with $1.5 \mathrm{ml}$ of $50 \%$ methanol for $1 \mathrm{~h}$ in an ultrasonic bath, then at $4{ }^{\circ} \mathrm{C}$ for $24 \mathrm{~h}$, and for another hour in an ultrasonic bath followed by centrifugation for 5 min at 13946 g (LACE24 Table Top Centrifuge, COLO, Novo Mesto, Slovenia). The supernatants were filtered through $0.45-\mu \mathrm{m}$ PTFE syringe filters before injection. For determination of anti-hyperglycemic and anti-inflammatory activity, $100 \mathrm{mg}$ of FDSP were mixed with $1 \mathrm{ml}$ of potassium phosphate buffer $(10 \mathrm{mM}, \mathrm{pH} 7)$ and vortexed for $1 \mathrm{~min}$, and then centrifuged for $2 \mathrm{~min}$. The supernatants were filtered through $0.45-\mu \mathrm{m}$ PTFE syringe filters.

Pigments in FDSP

Total chlorophyll (TChl), chlorophyll a (Chl a) and chlorophyll b (Chl b) contents

TChl, Chl a and Chl b contents were determined according to Lichtenthaler [41]. Acetone FDSP extracts extracts were analysed at 645 and $663 \mathrm{~nm}$, and chlorophyll contents were calculated using the formulas:

$$
\begin{aligned}
& \text { TChl }(\mu \mathrm{g} / \mathrm{ml})=\left(20.20 \times \mathrm{A}_{645}+8.02 \times \mathrm{A}_{663}\right) \\
& \text { Chl a }(\mu \mathrm{g} / \mathrm{ml})=\left(11.24 \times \mathrm{A}_{663}+2.04 \times \mathrm{A}_{645}\right) \\
& \text { Chl b }(\mu \mathrm{g} / \mathrm{ml})=\left(20.13 \times \mathrm{A}_{645}+4.19 \times \mathrm{A}_{663}\right)
\end{aligned}
$$

where $A_{645}$ and $A_{663}$ are the absorbances of FDSP acetone extracts at 645 and $663 \mathrm{~nm}$, respectively. TChl, Chl a and Chl b were calculated as mg of chlorophyll per $100 \mathrm{~g}$ FDSP dry matter (dm).

Total carotenoids content (TC)

Contents of total carotenoids in FDSP were determined according to the Lichtenthaler [41]. Absorbances of acetone FDSP extracts were read at $470 \mathrm{~nm}$. TC was calculated according to the formula:

$$
\mathrm{TC}(\mu \mathrm{g} / \mathrm{ml})=\left(\left(1000 \times \mathrm{A}_{470}-1.90 \times \mathrm{Chl} \mathrm{a}-63.14 \times \mathrm{Chl} b\right) / 214\right)
$$

where $A_{470}$ is the absorbance of FDSP acetone extract at $470 \mathrm{~nm}$. Finally, the results were calculated as $\mathrm{mg}$ of carotenoids per $100 \mathrm{~g}$ FDSP $\mathrm{dm}$.

Colorimetric measurements (CIE)

Colour measurements were analyzed by considering the CIELab colour system [42]. Colour characteristics were measured by placing the FDSP in a $15 \mathrm{~mm}$ thick and transparent plastic cell without cover and by using a black plate as the background to standardize the measurements. The chromameter consisted of an $8 \mathrm{~mm}$ diameter measuring area and diffuse illumination/viewing was

This article is protected by copyright. All rights reserved. 
utilized. The colour characteristics of CIE L*, a*, b* were calibrated against a standard white plate. Data were the average of triplicate measures on equidistant points of the FDSP. All the procedures were conducted at room temperature in the laboratory. Chroma or saturation was calculated as: $C^{*} a b=\left(a * 2+b^{*} 2\right)^{1 / 2}$, which is related to the intensity of colour, and the hue angle (hab $\left.{ }^{\circ}\right)$ was calculated according to the formula: hab $=\arctan \left(b^{*} / a^{*}\right)$.

Phenolics in FDSP

Total phenolic content (TPC)

TPC of methanolic FDSP extracts were evaluated using the Folin-Ciocalteu assay as described by Singleton et al. [43]. The results are expressed in $\mathrm{mg}$ gallic acid equivalent (GAE) in $\mathrm{mg} / 100 \mathrm{~g}$ FDSP $\mathrm{dm}$.

Total flavonoids content (TFC)

TFC of methanolic FDSP extracts were estimated using a method by Zhishen et al. [44] and the results were expressed as rutin equivalents (RE) in $\mathrm{mg} / 100 \mathrm{~g}$ FDSP dm.

Individual phenolic compounds

HPLC separation and quantification of phenolic compounds in FDSP extracts was performed according to Aborus et al. [17]. Chromatograms were recorded using different wavelengths for individual phenolic compounds. Phenolic compounds were separated using Luna C-18 RP column, 5 $\mu \mathrm{m}, 250 \times 4.6 \mathrm{~mm}$ (Phenomenex, Torrance, CA, USA) with a C18 guard column, $4 \times 30 \mathrm{~mm}$ (Phenomenex, Torrance, CA, USA). Gradient elution was performed using acetonitrile (A) and $1 \%$ formic acid (B) mobile phases, at flow rates of $1 \mathrm{ml} / \mathrm{min}$, following the gradient profile: 0 - $10 \mathrm{~min}$ from $10 \%$ to $25 \%$ A; 10 - 20 min linear rise up to $60 \%$; and from 20 min to 30 min linear rise up to $70 \% A$, followed by 10 min reverse to initial $10 \% A$ with 5 min of equilibration time.

In vitro digestion of phenolics

Simulation of in vitro digestion of phenolics from FDSP was carried out by exposing FDSP to simulated gastric and intestinal fluids, separately, according to Saikia et al. [45]. Total phenolics in gastric and intestinal digestates were analysed by Folin-Ciocalteu method, as described above.

Determination of FDSP bioactivities

Antioxidant capacity by DPPH assay $\left(\mathrm{AC}_{\mathrm{DPPH}}\right)$

To determine the antioxidant capacities (AC) of FDSP by the DPPH assay the method reported by Brand-Williams et al. [46] was used. Briefly, $1 \mathrm{ml}$ of extract solution was mixed with $2 \mathrm{ml}$ of DPPH methanol solution $(2 \mathrm{mM})$. For control measurement extract was replaced with water. The mixture was left in dark at room temperature for $30 \mathrm{~min}$, and then the absorbance was read at $517 \mathrm{~nm}$.

$A C_{D P P H}$ was calculated following the formula: $A C_{D P P H}(\%)=\left(1-A_{S} / A_{C}\right) \times 100$, where $A_{C}$ and and $A_{S}$ are the absorbances of the control and sample, respectively. The results were expressed as the $\mathrm{EC}_{50}{ }^{\mathrm{DPPH}}$ values (inhibitory concentration of the extract that decreases $50 \%$ of the initial $\mathrm{DPPH}^{\bullet}$ absorbance) and as $\mathrm{mg}$ and mmol Trolox equivalent (TE) per $100 \mathrm{~g}$ FDSP $\mathrm{dm}$.

This article is protected by copyright. All rights reserved. 
Antioxidant capacity by ABTS assay $\left(\mathrm{AC}_{\mathrm{ABTS}}\right)$

Antioxidant capacity of the FDSP samples was tested also by ABTS assay, according to the method reported by Tumbas Šaponjac et al. [47]. The $A C_{A B T s}$ values were calculated using the formula: $A C_{A B T S}$ $(\%)=\left(1-A_{S} / A_{C}\right) \times 100$, where $A_{C}$ and $A_{S}$ are absorbances of the control and the sample, respectively. The results were expressed as $\mathrm{EC}_{50}{ }^{\mathrm{ABTS}}$ (the concentration of extract that decreases the initial $\mathrm{ABTS}^{+}{ }^{\bullet}$ absorbance by $50 \%$ ) and also as $\mathrm{mg}$ and mmol TE per $100 \mathrm{~g}$ FDSP $\mathrm{dm}$.

Reducing power assay (RP)

$\mathrm{RP}$ of samples was tested by the method from Oyaizu [48]. Results were expressed as $\mathrm{EC}_{0.5}{ }^{\mathrm{RP}}$ (FDSP extract concentration providing 0.5 absorbance, calculated from the graph presenting absorbance at $700 \mathrm{~nm}$ vs. extract concentration) as well as $\mathrm{mg}$ and mmol TE per $100 \mathrm{~g}$ FDSP $\mathrm{dm}$.

Anti-hyperglycemic activity (AHgA) by $\alpha$-glucosidase bioassay

The ability of FDSP extracts to inhibit the release of $p$-nitrophenol from 4-nitrophenyl $\alpha$-Dglucopyranoside (substrate) initiated by enzymatic activity of $\alpha$-glucosidase was used as a marker for evaluating AHgA [47]. The reaction was performed at $37^{\circ} \mathrm{C}$ for $10 \mathrm{~min}$. The absorbance of $p$ nitrophenol was measured at $405 \mathrm{~nm}$. $\mathrm{AHgA}$ was calculated using the equation: $\mathrm{AHgA}(\%)=\left(\Delta \mathrm{A}_{c}-\right.$ $\left.\Delta A_{s}\right) / \Delta A_{c} \times 100$, where $\Delta A_{c}$ and $\Delta A_{s}$ are the differences in absorbance of control reaction mixture and reaction mixture containing sample before and $10 \mathrm{~min}$ after the incubation with enzyme. The results were expressed as $\mathrm{EC}_{50}{ }^{\mathrm{AHgA}}$ (the concentration of FDSP providing $50 \%$ of enzyme inhibition, calculated from the graph presenting AHgA vs. extract concentration).

Anti-inflammatory activity (AIA) by protein denaturation assay

The extent of FDSP extract inhibition of protein denaturation was used as an in vitro marker for antiinflammatrory activity (AIA), according to the method described by Ullah et al. [49]. Briefly, FDSP extract $(2 \mathrm{ml})$ was incubated with egg albumin from fresh hen egg $(0.2 \mathrm{ml})$ and buffered saline phosphate $\left(\mathrm{pH} \mathrm{6.4)}\right.$ at $37^{\circ} \mathrm{C}$ for $15 \mathrm{~min}$ and then at $70{ }^{\circ} \mathrm{C}$ for $5 \mathrm{~min}$. After cooling, the absorbance of the solution was measured at $660 \mathrm{~nm}$. Diclofenac sodium was used as a reference standard. The percentage of inhibition of protein denaturation was calculated as AIA $(\%)=\left(1-A_{S} / A_{c}\right) \times 100$, where $A_{s}$ and $A_{c}$ are the absorbances of the sample and the control, respectively. The results were expressed as $\mathrm{EC}_{50}{ }^{\mathrm{AlA}}$ (the concentration of FDSP extracts providing $50 \%$ inhibition of protein denaturation).

Statistical analysis

All experiments were run in triplicate and reported as mean \pm SD. Significant differences between means were analyzed by ANOVA and Tukey-Kramer multiple comparison test, adopting 95\% ( $p \leq$ 0.05 ) as the level of significance. $\mathrm{EC}_{50} / \mathrm{EC}_{0.5}$ was calculated by using the best-fit regression model.

This article is protected by copyright. All rights reserved. 
Linear relationship was estimated using the Pearson's linear correlation coefficient $(r)$. Data was analyzed using OriginPro 8 SR2 software (OriginLab Corporation, MA, USA) and Microsoft Office Excel 2010 software.

\section{Acknowledgements}

The authors would like to thank Provincial Secretariat for Higher Education and Scientific Research, Autonomous Province of Vojvodina, Republic of Serbia, for financial support (Grant No. 114-4512079/2016-03). Naji Aborus would like to express his gratitude to the Ministry of Higher Education in Libya for the PhD grant supporting this research. The authors also present their sincere thanks to Dr. Boris Popovic from the Faculty of Agriculture, University of Novi Sad, for providing the laboratory for germination.

\section{Author Contribution Statement}

Naji Elhadi Aborus, Vesna Tumbas Šaponjac, Jelena Vulić and Vanja Šeregelj have performed the experiments. Manuscript was written by Naji Elhadi Aborus, Vesna Tumbas Šaponjac, Jasna Čanadanović-Brunet and Gordana Ćetković. Alyssa Hidalgo performed and discussed the results of the statistical analysis.

\section{References}

[1] O. N. Donkor, L. Stojanovska, P. Ginn, J. Ashton, T. Vasiljevic, 'Germinated grains-Sources of bioactive compounds', Food Chem. 2012, 135, 950-959.

[2] P. Pajak, R. Socha, D. Gałkowska, J. Znowski, T. Fortuna, 'Phenolic profile and antioxidant activity in selected seeds and sprouts', Food Chem. 2014, 143, 300-306.

[3] A. P. Vale, J. Santos, N. V. Brito, D. Fernandes, E. Rosa, M. B. P. Oliveira, 'Evaluating the impact of sprouting conditions on the glucosinolate content of Brassica oleracea sprouts', Phytochemistry 2015, 115, 252-260.

[4] P. V. Hung, T. Maeda, S. Yamamoto, N. Morita, 'Effects of germination on nutritional composition of waxy wheat', J. Sci. Food Agric. 2012, 92, 667-672.

[5] N. Komatsuzaki, K. Tsukahara, H. Toyoshima, T. Suzuki, N. Shimizu, T. Kimura, 'Effect of soaking and gaseous treatment on GABA content in germinated brown rice', J. Food Eng. 2007, 78, 556-560.

[6] S. Žilić, Z. Basić, V. Hadži - Tašković Šukalović, V. Maksimović, M. Janković, M. Filipović, 'Can the sprouting process applied to wheat improve the contents of vitamins and phenolic compounds and antioxidant capacity of the flour?', Int. J. Food Sci. Technol. 2014, 49, $1040-1047$.

[7] A. Kaukovirta-Norja, P. Lehtinen, in 'Technology of functional cereal products', Ed. B. R. Hamaker, Woodhead Publishing Limited, Abington, Cambridge, 2008, p. 215.

[8] P. C. Morris, J. H. Bryce, in 'Cereal Biotechnology', Eds. P. C. Morris, J. H. Bryce, Woodhead Publishing Limited, Abington, Cambridge, 2000, p. 10.

[9] Z. Šramková, E. Gregová, E. Šturdík, 'Chemical composition and nutritional quality of wheat grain', Acta Chim. Slov. 2009, 2, 115-138.

[10] O. K. Chun, D. O. Kim, N. Smith, D. Schroeder, J. T. Han, C. Y. Lee, 'Daily consumption of phenolics and total antioxidant capacity from fruit and vegetables in the American diet', J. Sci. Food Agric. 2005, 85, 1715-1724.

[11] S. Ghio, A. A. Barresi, G. Rovero, 'A comparison of evaporative and conventional freezing prior to freeze-drying of fruits and vegetables', Trans IchemE 2000, 78, 187-192.

[12] G. R. De Nicola, M. Bagatta, E. Pagnotta, D. Angelino, L. Gennari, P. Ninfali, P. Rollin, R. lori, 'Comparison of bioactive phytochemical content and release of isothiocyanates in selected brassica sprouts', Food Chem. 2013, 141, 297-303.

This article is protected by copyright. All rights reserved. 
[13] M. Busheva, G. Garab, E. Liker, Z. Tóth, M. Széll, F. Nagy, 'Diurnal fluctuations in the content and functional properties of the light harvesting chlorophyll $a / b$ complex in thylakoid membranes', Plant Physiol. 1991, 95, 997-1003.

[14] S. Mattioli, A. Dal Bosco, M. Martino, S. Ruggeri, O. Marconi, V. Sileoni, B. Falcinelli, C. Castellini, P. Benincasa, 'Alfalfa and flax sprouts supplementation enriches the content of bioactive compounds and lowers the cholesterol in hen egg', J Funct. Foods 2016, 22, 454-462.

[15] L. Plaza, B. de Ancos, M. P. Cano, 'Nutritional and health-related compounds in sprouts and seeds of soybean (Glycine max), wheat (Triticum aestivum L.) and alfalfa (Medicago sativa) treated by a new drying method', Eur. Food Res. Technol. 2003, 216, 138-144.

[16] L. Alvarez-Jubete, H. Wijngaard, E. K. Arendt, E. Gallagher, 'Polyphenol composition and in vitro antioxidant activity of amaranth, quinoa buckwheat and wheat as affected by sprouting and baking', Food Chem. 2010, 119, 770-778.

[17] N. E. Aborus, J. Čanadanović - Brunet, G. Ćetković, V. Tumbas Šaponjac, J. Vulić, N. llić, 'Powdered barley sprouts: composition, functionality and polyphenol digestibility', Int. J. Food Sci. Technol. 2017, 52, 231-238.

[18] B. Tian, B. Xie, J. Shi, J. Wu, Y. Cai, T. Xu, S. Xue, Q. Deng, 'Physicochemical changes of oat seeds during germination', Food Chem. 2010, 119, 11951200.

[19] R. A. Carciochi, G. D. Manrique, K. Dimitrov, 'Changes in phenolic composition and antioxidant activity during germination of quinoa seeds (Chenopodium quinoa Willd.)', Int. Food Res. J. 2014, 21, 767-773.

[20] P. V. Hung, D. W. Hatcher, W. Barker, 'Phenolic acid composition of sprouted wheats by ultra-performance liquid chromatography (UPLC) and their antioxidant activities', Food Chem. 2011, 126, 1896-1901.

[21] I. McMurrough, T. Baert, 'Identification of proanthocyanidins in beer and their direct measurement with a dual electrode electrochemical detector', J. Inst. Brew. 1994, 100, 409-416.

[22] S. Pérez-Balibrea, D. A. Moreno, C. García-Viguera, 'Genotypic effects on the phytochemical quality of seeds and sprouts from commercial broccoli cultivars', Food Chem. 2011, 125, 348-354.

[23] R. J. Green, A. S. Murphy, B. Schulz, B. A. Watkins, M. G. Ferruzzi, 'Common tea formulations modulate in vitro digestive recovery of green tea catechins', Mol. Nutr. Food Res. 2007, 51, 1152-1162.

[24] M. H. Abdille, R. P. Singh, G. K. Jayaprakasha, B. S. Jena, 'Antioxidant activity of the extracts from Dilleniaindica fruits', Food Chem. 2005, 90, 891-896.

[25] Z. Hodzic, H. Pasalic, A. Memisevic, M. Srabovic, M. Saletovic, M. Poljakovic, 'The influence of total phenols content on antioxidant capacity in the whole grain extracts', Eur. J. Sci. Res. 2009, 28, 471-477.

[26] G. K. Jayaprakasha, B. S. Patil, 'In vitro evaluation of the antioxidant activities in fruit extracts from citron and blood orange', Food Chem. 2007, 101, 410-418.

[27] G. J. McDougall, F. Shpiro, P. Dobson, P. Smith, A. Blake, D. Stewart, 'Different Polyphenolic Components of Soft Fruits Inhibit $\alpha$-Amylase and $\alpha$ Glucosidase', J. Agric. Food Chem. 2005, 53, 2760-2766.

[28] G. J. McDougall, D. Stewart, 'The inhibitory effects of berry polyphenols on digestive enzymes', Biofactors 2005, 23, 189-195.

[29] V. Tumbas Šaponjac, A. Gironés-Vilaplana, S. Djilas, P. Mena, G. Ćetković, D. A. Moreno, M. Vinčić, 'Chemical composition and potential bioactivity of strawberry pomace', RSC Adv. 2015, 5, 5397-5405.

[30] A. S. Boath, D. Stewart, G. J. McDougall, 'Berry components inhibit $\alpha$-glucosidase in vitro: Synergies between acarbose and polyphenols from black currant and rowanberry', Food Chem. 2012, 135, 929-936.

[31] F. Giampieri, S. Tulipani, J. M. Alvarez-Suarez, J. L. Quiles, B. Mezzetti, M. Battino, 'The strawberry: composition, nutritional quality, and impact on human health', Nutrition 2012, 28, 9-19.

[32] G. J. McDougall, H. A. Ross, M. Ikeji, D. Stewart, 'Berry extracts exert different antiproliferative effects against cervical and colon cancer cells grown in vitro', J. Agric. Food Chem. 2008, 56, 3016-3023.

[33] S. Chandra, P. Chatterjee, P. Dey, S. Bhattacharya, 'Evaluation of in vitro anti-inflammatory activity of coffee against the denaturation of protein', Asian Pac. J. Trop. Biomed. 2012, 2, S178-S180.

[34] H. L. Dimberg, O. Theander, H. Lingnert, 'Avenanthramides - A group of phenolic antioxidants in oats', Cereal Chem. 1993, 70, 637-641.

[35] M. Skoglund, 'Phenolic compounds in oats: Effects of steeping, germination and related enzymes', PhD thesis, Swedish University, Uppsala, 2008.

[36] P. Vale, H. Cidade, M. Pinto, M. B. Oliveira, 'Effect of sprouting and light cycle on antioxidant activity of Brassica oleracea varieties', Food Chem. 2014, $165,379-387$.

[37] A. Aires, C. Fernandes, R. Carvalho, R. N. Bennett, M. J. Saavedra, E. A. S. Rosa, 'Seasonal Effects on Bioactive Compounds and Antioxidant Capacity of Six Economically Important Brassica Vegetables', Molecules 2011, 16, 6816-6832.

This article is protected by copyright. All rights reserved. 
[38] G. Kouri, D. Tsimogiannis, H. Bardouki, V. Oreopoulou, 'Extraction and analysis of antioxidant components from Origanum dictamnus', Innov. Food Sci. Emerg. Technol. 2007, 8, 155-162.

[39] J. Wang, G. Mazza, 'Effects of anthocyanins and other phenolic compounds on the production of tumor necrosis factor $\alpha$ in LPS/IFN- $\gamma$-activated RAW 264.7 macrophages', J. Agric. Food Chem. 2002, 50, 4183-4189.

[40] F. Yang, T. K. Basu, B. Ooraikul, 'Studies on germination conditions and antioxidant contents of wheat grain', Int. J. Food Sci. Nutr. 2001, 52, 319-330.

[41] H. K. Lichtenthaler, 'Chlorophylls and carotenoids: pigments of photosynthetic biomembranes', Methods Enzymol. 1987, 148, $350-382$.

[42] CIE International Commission on Illumination, Colorimetry, 'Official Recommendation of the International Commission on Illumination, Publication CIE No. (E-1.31)', Paris, France: Bureau Central de la CIE, 1976.

[43] V. L. Singleton, R. Orthofer, R. M. Lamuela-Raventos, in 'Methods in Enzymology. Oxidant and Antioxidant (part A)' Ed. L. Packer, Academic Press, San Diego, USA, 1999, p. 152

[44] J. Zhishen, T. Mengcheng, W. Jianming, 'The determination of flavonoid contents in mulberry and their scavenging effects on superoxide radicals', Food Chem. 1999, 64, 555-559.

[45] S. Saikia, N. K. Mahnot, C. L. Mahanta, 'Optimisation of phenolic extraction from Averrhoa carambola pomace by response surface methodology and its microencapsulation by spray and freeze drying', Food Chem. 2015, 171, 144-152.

[46] W. Brand-Williams, M. E. Cuvelier, C. Berset, 'Use of a free radical method to evaluate antioxidant activity', LWT-Food Sci. Technol. 1995, 28, 25-30.

[47] V. Tumbas Šaponjac, A. Gironés - Vilaplana, S. Djilas, P. Mena, G. Ćetković, D. A. Moreno, M. Krunić, 'Anthocyanin profiles and biological properties of caneberry (Rubus spp.) press residues', J. Sci. Food Agric. 2014, 94, 2393-2400.

[48] M. Oyaizu, 'Studies on product of browning reaction prepared from glucose amine', Jpn. J. Nutr. 1986, 44, 307-315.

[49] A. M. Ullah, S. Zaman, F. Juhara, L. Akter, S. M. Tareq, E. H. Masum, R. Bhattacharjee, 'Evaluation of antinociceptive, in-vivo\&in-vitro anti-inflammatory activity of ethanolic extract of Curcuma zedoaria rhizome', BMC Complement. Altern. Med. 2014, 14, 346-358.

This article is protected by copyright. All rights reserved. 